\title{
Utilização de agrotóxicos no assentamento três pontes, Município de Perolândia (go): fatores de risco á saúde
}

\author{
Use of agrochemicals in the seating three pontes, Perolânia \\ (go) Municipality: risk to health factors
}

\section{Utilización de agrotóxicos en el asiento tres puntos, Municipio de Perolania (go): factores de riesgo a la salud}

\author{
Celeni Miranda ${ }^{1}$ \\ Raquel Maria de Oliveira ${ }^{2}$ \\ Universidade Federal de Goiás, Brasil
}

\begin{abstract}
Resumo
Neste estudo foram entrevistados de um total de quarenta e três, doze lotes de assentados no Assentamento Três Pontes, que corresponde a 27,9\%, buscou também analisar a utilização de agrotóxicos na área de estudo pertencente ao município de Perolândia (GO), com vistas a revelar os impactos desses produtos para a saúde pública. A faixa etária dos sujeitos variam de 35 a 70 anos, podendo afirmar que trata-se de uma população adulta. O grau de escolaridade $72,7 \%$ possuem o Ensino Fundamental incompleto. Realidade que interfere quando se pensa que os produtos químicos requerem um grau de entendimento para manuseá-los. Para Florêncio et. Al. (2001), "A maioria dos trabalhadores afirma que não são capazes de entender as instruções e recomendações contidas nos rótulos dos produtos" (Florêncio, et. al.2001 p..51). Investigou-se o uso dos Equipamentos de Proteção Individual-EPIs; o conhecimento sobre o receituário agronômico, item obrigatório na aquisição desses produtos, e o descarte correto das embalagens vazias. Os resultados obtidos apontaram que dos doze lotes visitados 90,9\% reconhecem a importância dos EPis, mas não utilizam,

1 Graduada em Direito pela Universidade Euro Americana de Brasilia/DF, Pós graduada em Direito do Trabalho, Direito Publico e Saúde e Segurança no Trabalho, Mestre em Geografia pela Universidade Federal de Goiás, Regional Jatai-GO, professora de Geografia, Sociologia e Filosofia pelo Governo do Estado de Goiás. celeni.miranda@gmail.com

2 Doutora em Geografia, Professora adjunta da Escola de Medicina Veterinária e Zootecnia -AVZ da Universidade Federal de Goiás Campus Samambaia Goiânia-GO, raquelmoliveira@gmail.com
\end{abstract}


todos desconhecem o receituário agronômico e 30\% terceirizam o combate com agrotóxicos de suas propriedades. Trata-se de uma pesquisa qual quantitativa, optando-se pelo estudo de campo. Utilizou-se como instrumentos de coleta de dados: as observações, a aplicação de questionários e entrevistas semiestruturadas. Os sujeitos foram as famílias assentadas no Assentamento Três Pontes, apresentando a realidade dessa comunidade, sobre o seu modo de vida e principalmente a influência dos agrotóxicos em suas atividades produtivas, bem como sua conscientização e segurança na utilização dos mesmos. Verificou-se que no assentamento pesquisado as famílias utilizam agrotóxicos indiscriminadamente em suas lavouras.

Palavras-chave: Agrotóxico. Assentamento. Saúde. Meio Ambiente. Lavoura.

\begin{abstract}
In this study, a total of forty-three of the twelve settlements were interviewed in the Settlement of Three Bridges, which corresponds to $27.9 \%$. The study also analyzed the use of pesticides in the study area belonging to the municipality of Perolândia (GO), with views to reveal the impacts of these products on public health. The age range of the subjects varies from 35 to 70 years, being able to affirm that it is an adult population. The level of schooling $72.7 \%$ is incomplete. Reality that interferes when you think chemicals require a degree of understanding to handle them. For Florêncio et. Al. (2001), "Most workers state that they are not able to understand the instructions and recommendations contained in product labels" (Florêncio, et al. 2001, p. 51). We investigated the use of Personal Protective Equipment (PPE); the knowledge about the agronomic recipe, a mandatory item in the acquisition of these products, and the correct disposal of empty containers. The results showed that of the twelve lots visited $90.9 \%$ recognize the importance of the EPis, but they do not use it, all are not aware of the agronomic prescription and 30\% outsource the pesticide control of their properties. It is a qualitative research, opting for field study. Data collection instruments were used: the observations, the application of questionnaires and semi-structured interviews. The subjects were the families settled in the Settlement Three Bridges, presenting the reality of this community, about their way of life and mainly the influence of pesticides in their productive activities, as well as their awareness and safety in their use. It was verified that in the researched settlement families use agrochemicals indiscriminately in their crops.
\end{abstract}

Keywords: Agrotoxic. Settlement. Health. Environment. Agriculture.

Resumen: En este estudio fueron entrevistados de un total de cuarenta y tres, doce lotes de asentados en el Asentamiento Tres Puentes, que corresponde al 27,9\%, buscó también analizar la utilización de agrotóxicos en el área de estudio perteneciente al municipio de Perolândia (GO) con el fin de revelar los impactos de estos productos para la salud pública. El grupo de edad de los sujetos varía de 35 a 70 años, pudiendo afirmar que se trata de una población adulta. El grado de escolaridad $72,7 \%$ poseen la Enseñanza Fundamental incompleta. Realidad que interfiere cuando se piensa que los productos químicos requieren un grado de entendimiento para manipularlos. Para Florencio et. (2001), "La mayoría de los trabajadores afirman que no son capaces de entender las instrucciones y recomendaciones contenidas en las etiquetas de los productos" (Florencio, et al. Al 2001). Se investigó el uso de los Equipos de Protección Individual-EPIs; el conocimiento sobre el recetario agronómico, ítem obligatorio en la adquisición de esos productos, y el descarte correcto de los envases vacíos. Los resultados obtenidos apuntaron que de los doce lotes visitados el 90,9\% reconocen la importancia de los EPIS, pero no utilizan, todos desconocen el recetario agronómico y el 30\% tercerizan el combate con agrotóxicos de sus propiedades. Se trata de una encuesta cuantitativa, optando 
por el estudio de campo. Se utilizó como instrumentos de recolección de datos: las observaciones, la aplicación de cuestionarios y entrevistas semiestructuradas. Los sujetos fueron las familias asentadas en el Asentamiento Tres Puentes, presentando la realidad de esa comunidad, sobre su modo de vida y principalmente la influencia de los agrotóxicos en sus atividades produtivas, así como su concientización y seguridad en la utilización de los mismos. Se verificó que en el asentamiento investigado las familias utilizan agrotóxicos indiscriminadamente en sus cultivos.

Palabras clave: Agrotóxico. Arreglo. Salud Ambiental. La agricultura.

\section{Introdução}

A Microrregião do Sudoeste de Goiás ganhou notoriedade como uma região de agricultura capitalista consolidada, a partir dos anos 70, resultante das políticas públicas de desenvolvimento regional, traçadas pelo governo brasileiro (Ribeiro, 2011).

Este programa promoveu grandes transformações no espaço regional, especificamente em seu espaço agrário, materializando-se na paisagem regional por transformações de ordem técnica-sócio-econômica.

Na Microrregião há diversos usos e formas de exploração da terra, com predominância do cultivo de bananais e hortaliças, numa gradativa dependência dos insumos e agrotóxicos impostos pelo paradigma da modernização do capital. No Brasil, a modernização da agricultura se deu por algumas razões, dentre elas destacam-se: o aumento da produtividade do trabalho visando o lucro; a redução dos custos; os conflitos entre capital e latifúndio e a implantação do complexo agroindustrial no país (Brum, 1988).

A partir da constituição desses complexos, a agricultura passou a atender não só ao mercado externo, mas também à demanda do mercado interno.

Ainda na Microrregião há a predominância da criação de gado leiteiro, persistindo a agricultura camponesa, exercida por pequenos produtores que sobrevivem por meio de estratégias de combinação de práticas de ajuda mútua com o trabalho familiar, visando à reprodução social da família (Ribeiro, 2011).

Essas famílias são marginalizadas e sofrem dificuldades diversas que vão desde a dificuldade de acesso às linhas de crédito, à manutenção sociocultural da família no campo, até à conscientização dos perigos para a saúde e meio ambiente em longo prazo, pelo constante uso dos insumos agrícolas e agrotóxicos. 
Define-se o campesinato como: (...) um conjunto de práticas e valores que remetem a uma ordem moral que tem como valores nucleantes a família, o trabalho e a Terra. Trata-se de um modo de vida tradicional, constituído a partir de relações pessoais e imediatas, estruturadas em torno da família e de vínculos de solidariedade, informados pela linguagem de parentesco, tendo como unidade social básica a comunidade (Marques, 2004, p. 145).

Diante dessa realidade, este estudo tem como objetivo principal verificar a utilização dos agrotóxicos e os fatores de riscos desses produtos nas áreas analisadas (Assentamento Três Pontes - Perolândia - GO).

Este estudo faz parte de um trabalho de campo, promovido pelo Programa de Pós-graduação em Geografia (PPGeo), da Universidade Federal de Goiás (UFG) - Regional Jataí, realizado no mês de novembro de 2015, no Assentamento Três Pontes, município de Perolândia Goiás, e pela prática da pesquisa de campo do mestrado, em que foi visitado o assentamento rural, estabelecendo um diálogo participativo com treze famílias, que se disponibilizaram a participar da pesquisa.

As famílias visitadas no assentamento, na sua maioria, são naturais de Mineiros-GO, município situado a noventa quilômetros do Assentamento Rural. O fator preponderante na migração para o assentamento, após várias tentativas de subsistência na cidade, foi à necessidade de trabalhar a terra como única profissão aprendida ao longo de suas vidas. A maioria dos moradores encontra-se no assentamento, há mais de dez anos, e acompanhou todo o processo desde o acampamento do MST - Movimento dos Trabalhadores Rurais sem Terra, até a regularização do assentamento. O tamanho e localização dos lotes foram distribuídos de acordo com a ordem de chegada e tempo de espera no acampamento.

O diálogo com as famílias pesquisadas possibilitou-nos apresentar o cotidiano e as dificuldades enfrentadas por esses sujeitos, enfatizando a experiência com agrotóxicos, utilizados na produção de soja dos lotes. Um exemplo desse tipo de atividade foi apresentado por um pequeno agricultor, aposentado por invalidez, que expos sua experiência negativa, quase fatal, que colocou em risco sua saúde, com o uso de defensivos-químicos agrícolas (Aldrim DDT). Esse agricultor afirma que após essa experiência, e depois de receber instruções técnicas, aderiu-se às práticas ecológicas em seus cultivos. Salienta-se que esse pequeno produtor utilizou por anos esse tipo de agrotóxico, manuseando-o sem qualquer proteção, vez que também não tinha as informações e os esclarecimentos necessários. 
O presente estudo está dividido em três partes, que inicialmente corresponde à apresentação, posteriormente apresentam-se os riscos à saúde, de acordo com o entendimento de Órgãos do Governo; no segundo momento apresentam-se as experiências distintas dos pequenos produtores de agricultura familiar-camponesa com os agrotóxicos e por fim, as considerações sobre o que foi exposto, além das observações de campo e uma discussão sobre a influência no uso de agrotóxicos nas atividades e os fatores de risco a saúde humana.

\section{Área de estudo}

A Microrregião do Sudoeste de Goiás, compreendida entre os paralelos $16^{\circ} 27^{\prime}$ e $19^{\circ} 15^{\prime}$ de Latitude Sul e os meridianos $53^{\circ} 12^{\prime}$ e $50^{\circ} 12^{\prime}$ de Longitude Oeste, engloba 18 municípios, que totalizam uma área de $56.111,53 \mathrm{Km}^{2}$, correspondendo a 16, 49\% da área do Estado (IBGE, 2010). Neste estudo destacou-se a área que compreende o Assentamento Três Pontes - PerolândiaGO. A figura 1 apresenta a localização do referido assentamento.

Figura 1. Mapa de Localização do Assentamento Três Pontes no Município de Perolândia GO.

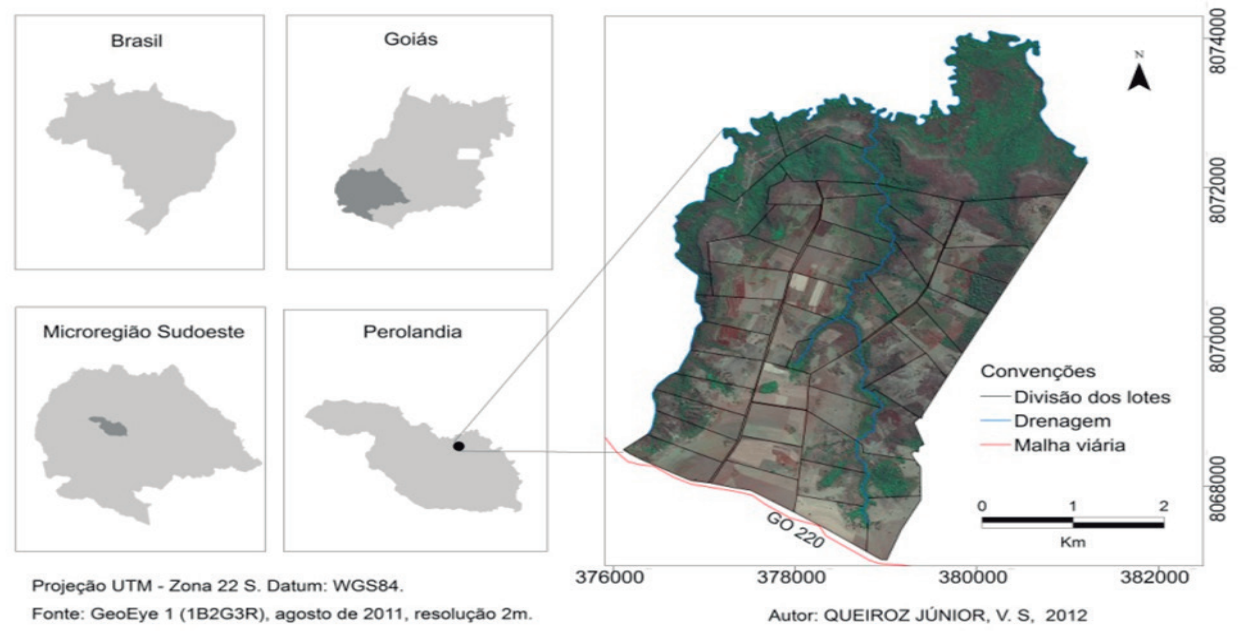

Fonte: Projeção UTM - Zona 22 S. Datum: WGS84.

Fonte: GeoEye 1 (1B2G3R), agosto de 2011, resolução $2 \mathrm{~m}$.

Autor: QUEIROZ JÚNIOR, v, s, 2012 
Nesta Microrregião atualmente estão em atividades os grandes produtores e as famílias camponesas - agricultura familiar. A área total de Produção de soja e milho colhidos em 2010 foi de 155.007 ha, com um total de 13.936.003 toneladas colhidas (IBGE, 2010).

O Assentamento Três Pontes compreendia uma grande propriedade que, após o falecimento dos patriarcas e do abandono pelos sucessores, fora invadida. Posteriormente, o INCRA comprou a terra e realizou a distribuição dos lotes 30 a 40 há por família de acordo com o tempo de espera de cada um dos atuais assentados.

O Assentamento é riquíssimo em nascentes e afluentes de importantes rios que abastecem aquela região e municípios vizinhos. Por sua vez, essas nascentes encontram-se ameaçadas em razão da substituição de seus cultivos pelo agronegócio.

As famílias pesquisadas demonstraram-se simples, receptivas e espontâneas, deixando claros seus anseios e expectativas, principalmente da profunda necessidade de orientação e ajuda na conscientização e necessidade no uso dos EPIs e os cuidados necessários com os agrotóxicos e com o correto descarte das embalagens vazias.

Segundo esses sujeitos, os incentivos do Governo Federal, por meio dos Programas de apoio ao Pequeno produtor, possibilitaram-lhes construir suas casas e comprar alguns maquinários necessários à produção de alimentos.

Informaram que iniciaram a substituição dos cultivos pela monocultura (soja e milho) a partir da visita de uma empresa estabelecida no município de Jatai(GO), há $98 \mathrm{~km}$, esta empresa ofereceu as sementes, os maquinários e engenheiros agrônomos, e que os engenheiros quando visitam os lotes indicam o tipo de produto e onde comprar os agrotóxicos. É a própria empresa que incentiva e compra os cultivos.

\section{Experiências distintas com os agrotóxicos}

Até o ano de 2011, havia uma diversidade de produção alimentícia no Assentamento Três Pontes (bananas, além de outros pequenos meios de produção: leite, suinocultura, hortaliças e frutas), porém com as facilidades e com os benefícios advindos do agronegócio a maioria das famílias assentadas aderiu ao cultivo de soja utilizando defensivos agrícolas em seus cultivares. 
Membros dessas famílias afirmaram que antes tudo era muito difícil, tinham dificuldade em vender o que produziam e havia menos incentivos do governo. Para eles existe uma vida antes e uma depois do agronegócio, "antes tudo era mais dificil, atualmente as coisas melhoraram bastante" (camponês).

Embora ainda exista família camponesa que produz alimentos para a sua subsistência e comercialização, há também aquelas que cultivam soja nos seus lotes, outros alugam parte de sua parcela para o agronegócio e outros que ao contrário, criam gado de leite.

E o que é mais grave, é que as residências e os cultivos de frutas, na maioria dos lotes, ficam a poucos metros de distância das lavouras, expostos, assim, aos agrotóxicos. A Figura 2 apresenta a proximidade das lavouras das residências.

Figura 2: Proximidade das lavouras das residências

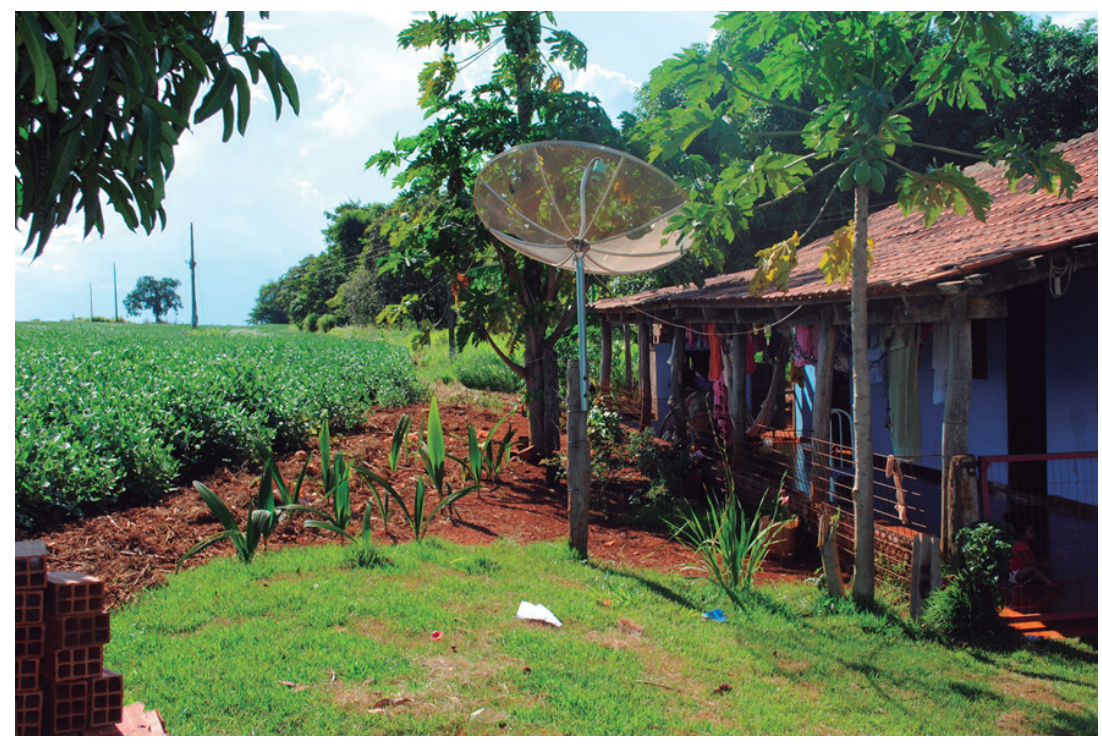

Fonte: Miranda C (2016).

De acordo com o Instituto Nacional do Câncer - INCA - vários tipos de câncer estão ligados à exposição aos agrotóxicos, e cada brasileiro, para o ano de 2015/16, consumiu, em média/ano, 7,5 litros de agrotóxicos/ano. 
Entre as muitas dificuldades enfrentadas na plantação e manutenção, de cultivos variados, também apresentou dificuldade na comercialização por meio de políticas públicas, como a do PAA (programa de aquisição de alimentos) ou se vende às empresas ligadas ao ramo alimentício, ou se dispendem a participar de feiras nas cidades mais próximas, que segundo eles é mais vantajoso.

Por todas essas dificuldades a tendência foi deixar a agricultura de subsistência. De acordo com Fonseca et al. (2010), a agricultura de subsistência teve seu valor, primeiro para a ocupação de terras, sendo o mote para se garantir um quinhão, depois na organização familiar.

Após essas considerações, o pequeno agricultor familiar se viu diante de uma cadeia produtiva e vantajosa no cultivo exclusivo da soja, desencadeando outras preocupações, recorrendo ao controle químico (acefato) por conta da incidência de pragas e perda de frutos constantes. Não utilizando adequadamente os EPIs (equipamentos de proteção individual) mesmo sabendo dos riscos à saúde, admitem não possuir apoio técnico ou educacional para lidar corretamente com essas questões e manejo de pragas.

Não intencionalmente, e por falta de orientação, as plantações de soja, na sua maioria, permeiam nascentes que abastecem importantes rios da região, e muitas delas não estão cercadas, havendo frequência de pisoteio de gado. Verificou-se que as embalagens de agrotóxicos são deixadas ao ar livre, muitas vezes, nas bordas das lavouras, outras reutilizadas para outros fins, como por exemplo, como depósitos de utilização doméstica; outras são enterradas e até mesmo queimadas.

De acordo com Crisolia (2005), nos países em desenvolvimento não se tem o cuidado, mínimo, com o uso de agrotóxicos, sendo comum o mau uso e o incorreto descarte de embalagens, muitas vezes abandonadas em leito de rios. Para o autor, ainda verifica-se manuseio de produtos em ambientes fechados; não cumprimento de prazos de aplicação e até mesmo excesso de aplicação de produtos. Como se verifica, falta aos agricultores e trabalhadores rurais, dos países em desenvolvimento, entendimento técnico-científico para o manejo de tais produtos. A Figura 3 apresenta o descuido dos assentados com as embalagens vazias de agrotóxicos.

Tal situação, considerada grave e prejudicial tanto à saúde quanto ao meio ambiente, além de contaminar a fauna e a flora, infiltra no solo 
Figura 3: Descuido com as embalagens vazias de agrotóxicos

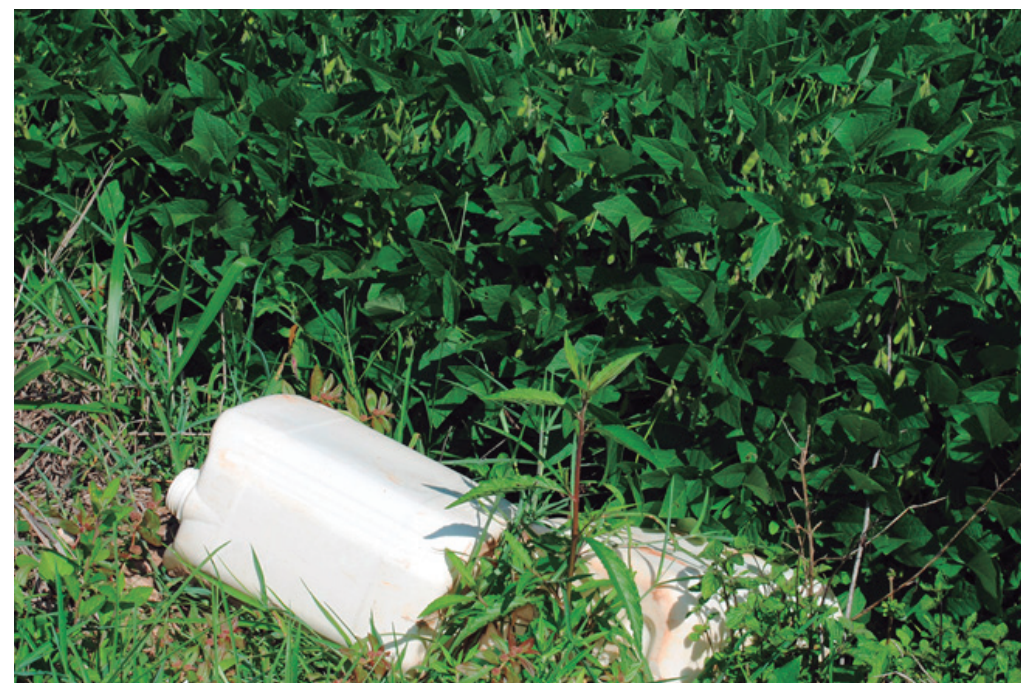

Fonte: Miranda C (2016).

e contamina os lençóis freáticos e canais fluviais, como no caso do Rio Claro importante rio que abastece municípios do sudoeste de Goiás. Muita das vezes essas famílias não recebem orientação sobre esse problema e o correto armazenamento e ou descarte das embalagens vazias.

O assentado, em sua maioria, não dispõe do devido conhecimento da gravidade no manuseio inadequado das embalagens, do grau de insalubridade e risco, principalmente com o produto cuja cor da embalagem antecipa os riscos insalubres, sendo o vermelho gravíssimo, mais ainda o manuseio sem a utilização adequada dos EPIs.

O agrotóxico utilizado nos cultivos de soja (Acefato) é extremamente tóxico para a saúde humana, o produto foi banido internacionalmente (Estado Unidos e União Europeia) e proibido no Brasil, conforme afirma (Carneiro et al. 2012).

Percebe-se que esse produto continua a ser comercializado ilegalmente no país, como no caso desse pequeno produtor familiar, que admitiu comprá-lo em outra localidade próxima ao seu município.

O processo de aquisição do referido agrotóxico, segundo as famílias assentadas, é feito pela empresa que controla toda cadeia produtiva no Assentamento, informa onde o pequeno produtor deve comprar os produtos. 
Muitas vezes ocorre diretamente na empresa, onde o "cliente" explica como está ou o que está ocorrendo com seu cultivo e o atendente indica o agrotóxico, sem verificar realmente o problema.

Pelo que fica posto, o camponês decide o método e a quantidade de produto químico a ser aplicado na cultura. De modo geral, tal situação comprova a falta de fiscalização dos órgãos competentes, assistência técnica e ausência de orientação adequada a esses agricultores.

Os tipos de produtos utilizados pelos assentados podem ser bem maiores do que os informados, vez que no momento das entrevistas as pessoas podem não ter se lembrado de todos os agrotóxicos que utilizam, tendo informado apenas aqueles manipulados recentemente ou aqueles que julgam de maior complexidade.

Vale ressaltar que no assentamento, não há uma dosagem especifica para o uso dos produtos conforme determina a Legislação acerca dos receituário agronômico, as familias utilizam conforme o agrônomo orienta verbalmente.

Dos produtos mais utilizados, oito dos entrevistados informaram que utilizam o Roundup, glifosato, WG, Elatos, Brilhante, Brazuca, Nembos, Interprete, Atrasina, Sanssão, Fuselat, Priori, Atabom, Curi, Fortengue, Democlecil, 82018 e 200215, e três dos entrevistados informaram que utilizam vários produtos, sem citar os nomes. Importante lembrar que, a simples avaliação da frequência de uso dos agrotóxicos não é suficiente para demonstrar a complexidade da exposição.

Segundo as entrevistas, as principais formas de aplicação dos produtos químicos são: $70 \%$, por meio do pulverizador mecanizado, e 30\%, por meio do jato (Gafanhoto). O pulverizador costal manual, em razão do menor volume do tanque, há um número maior de operações, isso ocorre também um alto nível de exposição dérmica (NISHIYAMA, 2003). De acordo com a autora, a diferença na exposição dérmica é que a pulverização costal envolve principalmente a perna, enquanto que a pulverização tratorizada envolve as mãos.

Em relação à armazenagem dos agrotóxicos, 70\% armazenam os agrotóxicos em local fora de casa, junto com outros produtos químicos; $20 \%$ armazenam em local fora de casa e trancados em armários específicos para produtos químicos, e 10\% armazenam dentro de casa, próximo à cozinha. 
Neste estudo evidenciou-se que no caso de lavagem dos equipamentos a água é jogada diretamente no chão. Dos assentados entrevistados, $70 \%$ disseram que lavam os equipamentos na própria lavoura; $10 \%$ em lavajato específico e $20 \%$ no quintal de casa. Quanto às embalagens vazias, os efeitos da incorreta destinação refletem, principalmente, na contaminação ambiental.

Os resultados obtidos permitem ter uma noção sobre o tipo de destino que é dado às embalagens vazias por esse grupo de assentados. Dos entrevistados: 90\% recolhem as embalagens vazias e entregam ao Centro de Triagem e Reciclagem, e 10\% revelaram que deixa em algum lugar no campo ou queima.

Essa problemática vai de encontro à Lei ${ }^{0} 7.802 / 1989$, que em seu artigo $10^{\circ}$ que trata da competência dos Estados e Distrito Federal, nos termos dos artigos 23 e 24 da Constituição Federal, que lhes compete: legislar sobre o uso, a produção, o consumo, o comércio e o armazenamento dos agrotóxicos, seus componentes e afins, bem como fiscalizar o uso, o consumo, o comércio, o armazenamento e o transporte interno.

\section{Fatores de riscos à saúde humana e ao Meio Ambiente}

A agricultura da década de 1990 até os dias atuais passou por várias transformações, em prol do aumento da produtividade, não se atentando para os perigos do uso de agrotóxicos para a saúde humana. Para Pignatti (2007), dentre os vários impactos da cadeia produtiva do agronegócio, os de maior relevância para a saúde e ambiente são as poluições e intoxicações agudas e crônicas relacionadas aos agrotóxicos, provocadas por inseticidas inibidores da colinesterase.

Nesse sentido, apresentam-se os riscos desses produtos para a saúde pública, principalmente para as populações expostas direta e indiretamente a esses produtos (Alves Filho, 2002).

Segundo o Ministério da Saúde, as principais doenças causadas por agrotóxico são: má formação fetal, dor de cabeça, diarreia, vômitos, desmaios, náuseas, problemas de rins, doenças de pele, irritação ocular e auditiva, depressão, lesão neurológica, câncer, neurite da coluna, neurológica cervical, problemas hormonais neurológicos e reprodutivos, dentre outras. E a pior maneira de aplicação desses produtos é por via aérea, em que os resíduos abrangem quilômetros de distância e os danos são ainda maiores e muitas vezes irreversíveis (Brasil, 2014). 
A prática de lavar equipamentos de aplicação e embalagens, jogando restos de agrotóxicos nas águas, é o modo de contaminação direta do meio ambiente e que atinge a população em geral. Outro modo é pelo ar, contaminado pela volatilização, além de transporte com partículas de poeira, o retorno dos inseticidas ao solo se dá principalmente por meio das chuvas, em menor grau pela deposição da poeira. O vento é o fator atmosférico que mais afeta a operação. Os agrotóxicos deixam resíduos onde são empregados, seja na sua forma química original, seja sob a forma de produtos degradados (Marques, 2004).

Carson $^{3}$ (2010) afirma que esses resíduos são encontrados no meio ambiente (atmosfera, águas de chuva, águas superficiais e subterrâneas e solos), em quantidades cada vez maiores, acumulando-se na cadeia alimentar, chegando até o homem. Assim a biosfera, (água, ar, solo) se vê atingida gravemente pela presença de resíduos de agrotóxicos, entre outros elementos corrompidos do qual o homem é o destinatário final.

Segundo estes pesquisadores, isso ocorre por meio de uma cadeia biológica, cujos escalões intermediários são os pastos, os animais e toda a sorte de produtos alimentícios, até o leite materno pode apresentar traços de agrotóxicos. De acordo com pesquisa sobre a contaminação dos agrotóxicos pelo leite materno, Pignati (2007) afirma que é impossível o uso totalmente seguro dos agrotóxicos, que penetra pela mucosa de pele, olho, orelha, inclusive pela respiração das pessoas. O efeito em longo prazo pode levar de cinco a dez anos para ser sentido.

Quando aplicado no sistema agrário ou áreas agrícolas os agrotóxicos sofrem uma série de reações, distribuindo-se nos diversos componentes desse ecossistema, contaminando-os, mesmo quando direcionados apenas às plantas, com vistas ao controle de insetos, fungos, plantas daninhas, etc. chegam ao solo posteriormente. Nos organismos terrestres o agrotóxico pode acumular-se nos vegetais e nos animais. A contaminação dos pássaros é outro aspecto relevante em termos ecológicos, eles representam um nível trófico relevante no controle e equilíbrio de insetos. Os pássaros podem ser contaminados, comendo insetos mortos e plantas embebidos por agrotóxicos. (Pignatti, 2007)

É necessário observar a classificação dos agrotóxicos de acordo com as orientações da ANVISA (Agencia Nacional de Vigilância Sanitária),

3 Primavera Silenciosa - 1945. 
Classe I, Faixa Vermelha, extremamente tóxico, Classe II, Faixa amarela, altamente tóxico, Classe III, faixa azul, mediamente tóxico e Classe IV, Faixa verde mediamente tóxico.

São mais de 30 tipos de agrotóxicos bastante consumidos no Brasil que são proibidos na União Europeia, como o endosulfan, retirado do mercado a partir de julho de 2013. O metamidofós saiu de circulação a partir de julho de 2012, e muitos outros que ainda necessitam da atenção da ANVISA, que continua revisando outros tipos de agrotóxicos.

Na classificação dos agrotóxicos, quanto a sua ação, o herbicida Roundup aparece como sendo o grupo de produtos mais utilizados pelos assentados, consequentemente com os que eles têm maior contato. A maioria dos sujeitos deste estudo relatou utilizar agrotóxicos, afirmou ainda ter sofrido pelo menos um episódio de intoxicação por agrotóxico.

Nesse sentido, infere-se que o contato com inúmeros tipos de produtos químicos, somado ao tempo de trabalho desses trabalhadores com esses tipos de produtos pode desencadear "quadros clínicos combinados que podem ser confundidos, inclusive, com outras doenças" (Nishiyama, 2003, p. 102).

O Quadro 1 apresenta o tempo que cada um dos entrevistados expostos aos agrotóxicos e o tipo de produto que manejam. Basta afirmar que a exposição baixas doses de agrotóxicos pode induzir morte celular, citotoxicidade, redução de viabilidade de células, entre outros (AUGUSTO et al., 2011, p. 257).

Quadro 1: Tempo de trabalho com os agrotóxicos e tipos de produtos utilizados

\begin{tabular}{|c|c|c|}
\hline Produtor & Produto & Tempo de uso \\
\hline A-1 & Glifosato/Roundup & 6 anos \\
\hline A-2 & Secante & 2 anos \\
\hline A-3 & Roundup /Democlecil & 40 anos \\
\hline A-4 & Glifosato & 4 anos \\
\hline A-5 & Glifosato/atrasina & 5 anos \\
\hline A-6 & Glifosato & 14 anos \\
\hline A-7 & Glifosato & 5 anos \\
\hline A-8 & Animais/nao sabe & 10 anos \\
\hline A-9 & Roundup & 5 anos \\
\hline A-10 & Glifosato/Roundup & 2 anos \\
\hline
\end{tabular}

Fonte: dados das entrevistas realizadas. 
Vale informar que um dos assentados relatou casos de intoxicação por agrotóxico na família. Outro informou que é alérgico ao produto, e por isso terceiriza a aplicação. Verifica-se que os assentados, sujeitos deste estudo, são passíveis dos impactos dos agrotóxicos, principalmente por causa do uso inadequado dos produtos; da falta de informação técnica; por negligências quanto ao uso de EPI's, além do descuido com as embalagens dos produtos.

Ressalta-se também que segundo o Instituto Nacional do Câncer (INCA) dezesseis tipos de câncer estão diretamente relacionados ao uso de agrotóxicos, nos casos mais graves podendo ocorrer, problemas renais, depressão, câncer e suicídio.

\section{Resultado e discussão}

A Secretaria Municipal de Saúde do Município de Perolândia (GO) informou que de 2010 a 2015 ocorreram cinco casos de intoxicação por agrotóxico, indicando os produtos causadores da intoxicação: Organo fosforado; Ciprimetrina; Ermoxonel Antrasina.

Quadro 2: Números de intoxicação por agrotóxicos em Perolândia (GO).

\begin{tabular}{|c|c|c|}
\hline Ano & Quantidade de casos & Exposição \\
\hline 2010 & 01 & Agrotóxico Lavoura \\
\hline 2011 & 01 & Organo fosforado \\
\hline 2012 & 0 & - \\
\hline 2013 & 01 & Ciprimetrina \\
\hline 2014 & 02 & Ermoxone/ Antrasina. \\
\hline 2015 & 0 & Não há registros \\
\hline
\end{tabular}

Fonte: dados das entrevistas realizadas.

A Secretaria de Saúde desse município, de acordo com funcionários, apresenta falhas nos registros, por problemas de cadastro nos anos mencionados. Segundo a Secretária, muitas informações se perderam ao longo do tempo, em razão da ausência de tecnologia (informática), e é possível que os dados sejam superiores aos cadastrados. 


\section{Considerações Finais}

No Assentamento Três Pontes Perolândia-GO, os assentados, pessoas humildes, manuseiam os produtos químicos, numa falsa ideia de enriquecimento rápido. $\mathrm{Na}$ verdade, suas vidas estão sendo ceifadas aos poucos. Observou-se que a escassez de capital próprio e disponibilidade de crédito a esses trabalhadores assentados, não interfere na utilização das novas tecnologias, inclusive dos agrotóxicos.

As experiências de cada uma dessas pessoas com os agrotóxicos demonstram os riscos causados à saúde e os principais problemas que estão sujeito a ocorrer. No caso das famílias assentadas, compreende-se que elas possuem clareza sobre essa prática prejudicial, porém, encontram-se aprisionadas a ela, por não ter outra opção para lidar com estratégia agroecológicas, recorrem-se ao tradicional para evitar as pragas e economizar tempo.

De acordo com uma família assentada, o uso do agrotóxico reduz o trabalho realizado, pois no lote reside apenas o casal, cuja rotina diária torna-se puxada e cansativa com intuito de manter sua subsistência no espaço geográfico rural.

Observaram-se no assentamento, que os jovens e as crianças saem do campo para as cidades para estudar, e uma vez que saem do campesinato não querem mais voltar, por isso as famílias campesinas estão reduzidas a casais e muitas vezes por pessoas idosas, um lamento apresentado por todos.

Em desabafo, eles afirmaram que não sabem do futuro do campesinato, porque chegará um ponto que eles também não conseguirão mais trabalhar, manter-se e sobreviver na terra. Assim, seus esforços para destruir um presente doloroso só levam a um futuro de maior incerteza. Mas se ele é trágico, é também esperançoso. “(...) se os rebeldes camponeses tomam parte na tragédia, participam também da esperança e, por isto, é deles o partido da Humanidade" (OLIVEIRA, 2007, p. 82).

Em relação às embalagens vazias dos produtos químicos, a situação é mais drástica, pois se verificou embalagens jogadas no meio da lavoura; crianças brincando com embalagens vazias dos produtos, entre outras irregularidades. Quanto ao armazenamento dos produtos, o procedimento é incorreto, uma vez que se guardam dentro das residências, muitas vezes próximos à cozinha ou aos quartos de dormir.

Por fim, acredita-se em um possível caminho de mudança, que seria uma transição agroecológica a ser desenvolvida tanto no assentamento, 
quanto na comunidade como uma estratégia de mudança paradigmática, um processo demorado e que precisa de outros suportes como políticas públicas adequadas à realidade do campo, assistência técnica efetiva e, principalmente, uma educação do campo e para o campo para manter os jovens e reproduzir o modo de vida rural.

\section{Referências}

Alves, J. P. (2002). Uso de Agrotóxicos no Brasil: Controle Social e Interesses Corporativos. São Paulo, Annablume: Fapesp.

Brasil (2015), Ministério da Saúde, disponível em: www.ministeriodasaude.go.gov.br. Acesso em: nov.

Brasil (2015), Lei $n^{\circ}$ 7.802, de 11 de julho de 1989. http://www.planalto. gov.br/ccivil_03/leis/L7802.htm. Acesso em 18.nov.

Brum, A.J., (1988) Modernização da Agricultura: Trigo e Soja, Petrópolis: Vozes,.

Carneiro, F. F., Augusto, L.G.S., Rigotto R.M., Friedrich, K. Campos, A. B., (2015) Dossiê ABRASCO: Um alerta sobre os impactos dos agrotóxicos na saúde. Rio de Janeiro, abril.

Carson, R. (2010), Primavera Silenciosa, 1907-1964-Traduzido por Claudia Sant'Anna Martins. Ed. SP: Gaia.

Castro, J, (2008). Geografia da fome. Rio de Janeiro: Civilização Brasileira. Coelho, C. N. (jul./ ago./ set 2001). 70 anos de política agrícola no Brasil (1931-2001). Revista de Política Agrícola, Brasília, 3, 3-58, (Edição especial).

Grissolia, C. K. (2005). Agrotóxicos: mutações, reprodução e câncer. Brasília: Editora Universidade de Brasília.

Fonseca, M. F. A. C.; colnago, N. F.; silva, G. R. R.; Fonseca, P. T (2010). Agricultura orgânica: regulamentos técnicos da produção animal e vegetal. Programa Rio Rural, Manual Técnico, v. 29.

Ferrari, A. (1986), Agrotóxicos: a praga da dominação. $2^{\mathrm{a}}$ ed. Porto Alegre, Mercado Aberto.

Ferrari D. (2016), Agricultores familiares, exclusão e desafios para inserção econômica na produção de leite em Santa Catarina. Informações Econômicas, São Paulo, v.35, n.1, jan. 2005. Disponível em http://www.iea.sp.gov.br/out/publicacoes/pdf/tec2-0105b.pdf. Acesso em: 25 fev.. 
IBGE-cidades (2010). hhttp://www.cidades.ibge.gov.br/, acesso em 20. nov..

Marques, M. I. M. (2004). Lugar do Modo de Vida Tradicional na Modernidade. In. Oliveira, Ariovaldo Umbelino de; Marques, Marta Inez Medeiros (orgs.). O Campo no Século XXI: território de vida, de luta e de construção da justiça social. São Paulo: Casa Amarela e Paz e Terra, (p. 145-158).

Nishiyama, P. (2003) Utilização de agrotóxicos em áreas de reforma agrária no Estado do Paraná - Tese de Doutorado, Fundação Oswaldo Cruz- Campinas, SP.

Oliveira, A. U. (2007), Modo de Produção Capitalista, Agricultura e Reforma Agrária. São Paulo: Labur Edições, 2007, 184p.

PignatI, W.A.(2007), Os riscos, agravos e vigilância em saúde no espaço de desenvolvimento do agronegócio no Mato Grosso [tese de doutorado]. Rio de Janeiro: Fiocruz/Ensp.

Ribeiro, D. D.(2003), Modernização da agricultura e (re) organização do espaço no município de Jataí - GO. Dissertação de mestrado em Geografia - Universidade Estadual Paulista, Faculdade de Ciências e Tecnologia. Presidente Prudente: [s.n.], 96 f. 